\title{
The Interrelation Between Textile Engineering Graduates' Results And Their Job Performance In Textile Industry Of Bangladesh
}

\author{
Md. Mahbubul Haque \\ Tanvir Ahmed Chowdhury \\ Md. Mominur Rahman
}

Department of Textile Engineering, Daffodil International University Shamima Akter Smrity

Department of Fabric Engineering, Bangladesh University of Textiles Md. Azharul Islam

Department of Textile Engineering, Mawlana Bhashani Science and Technology University

\section{Tariq Mahbub}

Department of Mechanical Engineering, Military Institute of Science and Technology

Doi:10.19044/esj.2021.v17n25p132

Submitted: 19 April 2021

Accepted: 06 July 2021

Published: 31 July 2021
Copyright 2021 Author(s)

Under Creative Commons BY-NC-ND 4.0 OPEN ACCESS

Cite As:

Haque M., Chowdhury T.A., Rahman M., Smrity S.A., Islam A. \& Mahbub T.(2021). The Interrelation Between Textile Engineering Graduates' Results And Their Job Performance In Textile Industry Of Bangladesh. European Scientific Journal, ESJ, 17(25), 132.

https://doi.org/10.19044/esj.2021.v17n25p132

\section{Abstract}

It has been a long that educators, employers, and researchers are trying to relate the university grades and job performance of graduates to improve the quality of teaching and make recruitment easy. However, a concrete conclusion is yet to achieve. In the current study, attempts were made to correlate the relationship between the grades obtained by the textile graduates of a university and their performance in the textile industries in Bangladesh using the Likert scale. Twenty dimensions of quality were identified and corresponding graduates' competence in these dimensions were evaluated and a relation was made with the grades obtained by the graduates. It was found that students with excellent academic results showed their excellence in the 
majority of the dimensions of quality over the students with average and poor results. Students with average and poor results also showed their excellence for few quality dimensions and no relation could be proposed. From this study, the authors concluded that, in general, the graduates' job performance was highly related to the GPA obtained by the graduates of that university.

Keywords: Academic Result, Job performance, Competence, Quality

\section{Introduction}

The textile sector is the largest foreign revenue-generating sector in Bangladesh. Each year a large number of fresh textile engineers enter the job market. It has been decades that educators have been trying to update and adjust their education and mode of teaching so that the graduates can perform well in their working place. Keeping this in mind, attempts have been made to correlate between university grades and their corresponding performance in the working area. A good number of examples are common around us who are outstanding in their university grades and job performance. Surprisingly, it is not also very uncommon that graduates with good grades in the university do not perform well in the workplace and graduates with poor grades in the university perform very well in their job. Considering these points of view, universities worldwide have been trying to find out the facts behind such mismatches of University grades and job performance. From the above perceptions, an attempt has been made to correlate university grades and their corresponding performance in the job place.

A novel hybrid algorithm, HLVQ, is proposed to predict students' academic performance and employability chances compared to present and earlier performance (K. Subhash Bhagavan, 2020). In contrast, tacit knowledge sharing obtained from academic performance is an important parameter for job performance and better workplace productivity (Carol P. Huie, 2020). But often, academic procrastination is very significant for academic achievement and task performance (Alexandre Gareau, 2019). On the other hand, perceptions of employability and academic performance both increased at the end of graduation to avail faster placements (Brooke HarrisReeves, 2017); that's why realistic job expectations is a potential predictor for academic achievement (Georg Krammer, 2016). By considering the phenomenon, meta-analysis was used by some groups where a positive relationship was found between academic performance and job performance (Nathan R. Kuncel, 2004).

Moreover students' procedural knowledge as cognitive factors sometimes predicts academic and post-academic success (Filip Lievens, 2012). Still, knowledge management from academic achievement can be an important factor for better performance and positively impacts innovation in 
the workplace (Mafeng Dauda Gyemanga, 2020) (Lina Al-Abbadia, 2020). Similarly, components of the knowledge management process show positive relation with the performance of an organization measured by its employees' satisfaction (Lekhanath Khanal, 2017). Finally, it has been observed that knowledge management significantly impacts human resource performances in the workplace (Mir Hamid Reza Torabia, 2016). Beyond those factors, academic performance and extracurricular activities participation approach distinctiveness in job performance (Luisa H. Pinto, 2017) ('In the eyes of the beholder': the influence of academic performance and extracurricular activities on the perceived employability of Chinese business graduates, 2018) and a good academic project performance aids the placement due to sharp practical skills (Tripti Mishra1, 2017) which can be a factor for satisfied job performance, in the same way proactive students with academic grades become an asset for employers (Alex Tymon, 2016) predicting a higher chance of effective job performance. Like other authors and research groups, this idea of academic qualification is a determining factor for job performance (FAITH, 2014).

It is still not justified whether a good university grade can foretell a good job performance. The volume of employment is quite large; a rigorous study on selection criteria is necessary. Unfortunately, no study took place to see if there is actually any relation between the grades a graduate earns in academia and his performance in the textile industry in Bangladesh. To meet this requirement, this study was conducted.

\section{Methodology}

The objective of this paper was to see the relationship between the performance of a student in their university and their performance in the industry. Performance in the University was assessed from the grades/GPA achieved by a student, while the performance in the industry was assessed by filling a questionnaire by an immediate supervisor. In fact, the study was conducted as part of a "Self-assessment survey", a project of the Institutional Quality Assurance Cell (IQAC) of the University Grants Commission of Bangladesh funded by the World Bank. IQAC provided a detailed manual containing questionnaires for various stakeholders of a university, including employers. For the current paper, we have used the questionnaire for employers. The questionnaire contains two parts for judging 20 quality parameters. The first part aims to see what an employer expects from a graduate regarding the 20 quality parameters. The purpose of the second part is to see to what extent a graduate could satisfy those expectations. For the study, fifty graduates from the department of textile engineering of a renowned private university in Bangladesh were selected. All the graduates have been working in the different types of textile industries in and around greater Dhaka. 
Based on GPA the graduates are classified into three groups e.g. (i) GPA 2.53.0, (ii) GPA 3.0-3.5 and (iii) GPA 3.5-4.0. It was observed that 10 graduates (20\% of the total number) were within GPA 2.50 to 3.00 are classified as poorperforming students, 25 graduates (50\% of the total number) were with GPA 3.00 to 3.50 are classified as average performing students and 15 graduates (30\% of the total number) were with GPA 3.50 to 4.00 are classified as good performing students. All the employers are encouraged to fill up a separate questionnaire form for each employee if more graduates from that respected university are working in the same industry. The employers are also encouraged to consult with the respected section head about the employee to ensure the accurateness of their response.
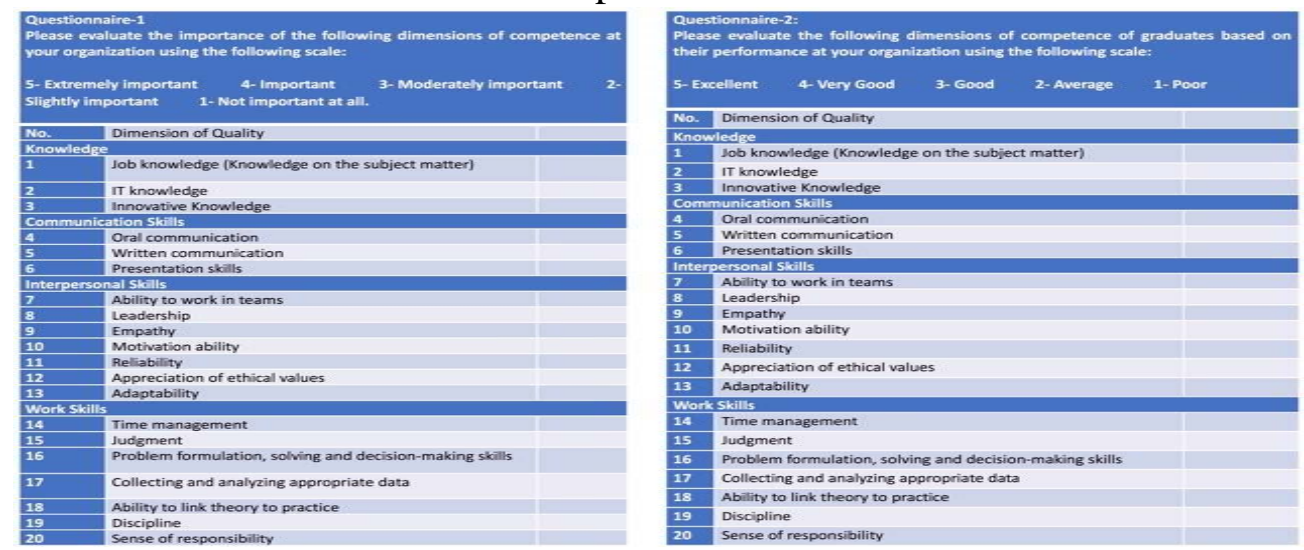

Figure 1. Sample Questionnaires for Survey

A sample questionnaire is given below to clearly understand the assessed quality of graduates in employment (IQAC Manuals, n.d.). Here, questionnaire 01 was used to assess the importance of different dimensions of quality and questionnaire 02 was used to assess graduates' competence.

Collecting all the data from the employers, they are processed and plotted to see the relationship between the three groups of graduates based on GPA and their performance based on these twenty qualities. These plots will show which group of students are most competent in industries.

\section{Result \& Discussion}

For all figures, the $\mathrm{X}$-axis indicates Likert Scale and $\mathrm{Y}$-axis indicates the competency of graduates. For the employer's expectancy, 1: not important, 2: slightly important, 3: moderately important, 4: important, 4: extremely important. For a graduate's competency, 1: poor, 2: average, 3: good, 4: very good, 5: excellent. 
Job knowledge

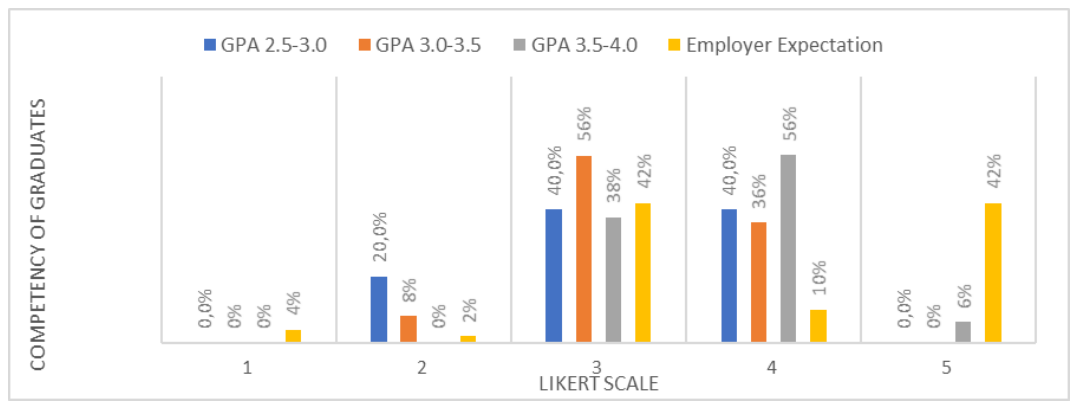

Figure 2. Competency of graduates and employer's expectancy vs Likert scale for job knowledge

The first quality that the study assessed is job knowledge. In figure 2, the employer's view of the graduates' importance of job knowledge and competency is plotted against Likert scale. Forty-one percent of the employers think job knowledge is extremely important (5 on the Likert scale), while another forty one percent think it is moderately important (3 on Likert scale). This shows the variability in the requirement of a certain quality in different sectors of the Textile industry. The competency of good performing students is visible by having $8 \%$ of the students get $5,56 \%$ get 4 , and $36 \%$ get 3 on the Likert scale. But interestingly, the two categories of students also did well on the scale. Since $41 \%$ of employers consider job knowledge to be somewhat important (3 on Likert scale), we can consider 3 to be an acceptable competency of the graduates. Figure 1 shows a total of $100 \%$ of good performing students, $92 \%$ of average performing students and $80 \%$ of poorperforming students get 3 or more on the Likert scale. This suggests that, though all categories of students look to be competent with respect to job knowledge, GPA has a positive relationship with Job knowledge.

\section{IT knowledge}

Figure 3 shows that $56 \%$ of the employers think IT knowledge is moderately important (3 on Likert scale). Hence, considering good IT knowledge (3 on Likert scale) is sufficient to show competency of graduates. Total $94 \%, 84 \%$ and $70 \%$ of good performing, average performing, and poor performing students respectively are average competent (3 on Likert scale). This figure also concludes GPA has a positive relationship with the competency of graduates in the job market. 


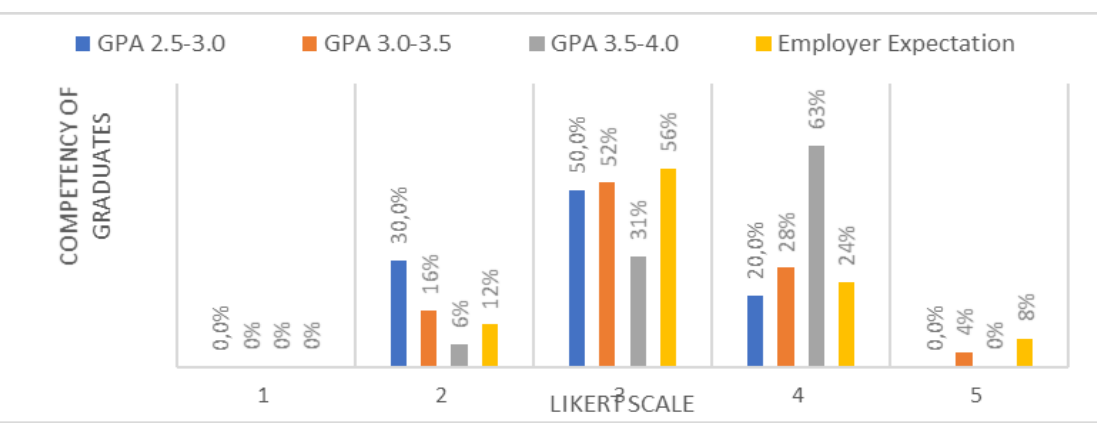

Figure 3. Competency of graduates and employer's expectancy vs Likert scale for IT knowledge

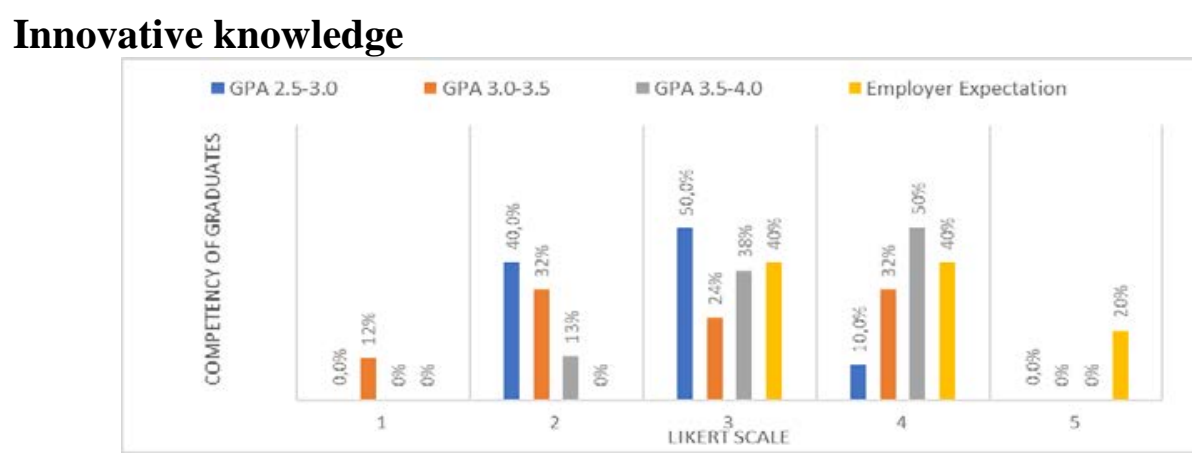

Figure 4. Competency of graduates and employer's expectation vs Likert scale for innovative knowledge

From the employer's point of view, innovative knowledge seems to be very important. A total of $60 \%$ of the employers think innovative knowledge is either important or extremely important. So, it is assumed Likert scale 4 is an acceptable value for the competency of graduates. The overall competence of graduates with respect to innovative knowledge seems to be poor having no graduates get excellent grades. However, $50 \%, 32 \%$ and $10 \%$ of good performing, average performing, and poor performing students respectively received 4 on the Likert scale. Here we again found a positive relationship between GPA and competency of graduates.

\section{Oral Knowledge}

Oral knowledge is clear to be very important in all the sectors. $60 \%$ of employers thinks it is important (4 on Likert scale), while $40 \%$ think it is extremely important (5 on Likert scale). Good performing students showed their dominance in this quality, too, with $57 \%$ getting 4 or more Likert scale. Total $44 \%$ and $30 \%$ of average performing and poor performing students respectively received 4 on the Likert scale. Once again, we again found a positive relationship between GPA and competency of graduates. The plot also shows, nearly $60 \%, 52 \%$ and $44 \%$ of poor-performing, average 
performing, and good performing students received good (3 on Likert scale), which indicates the good competence of the graduates.

Figure 5. Competency of graduates and employer's expectation vs Likert scale for oral knowledge

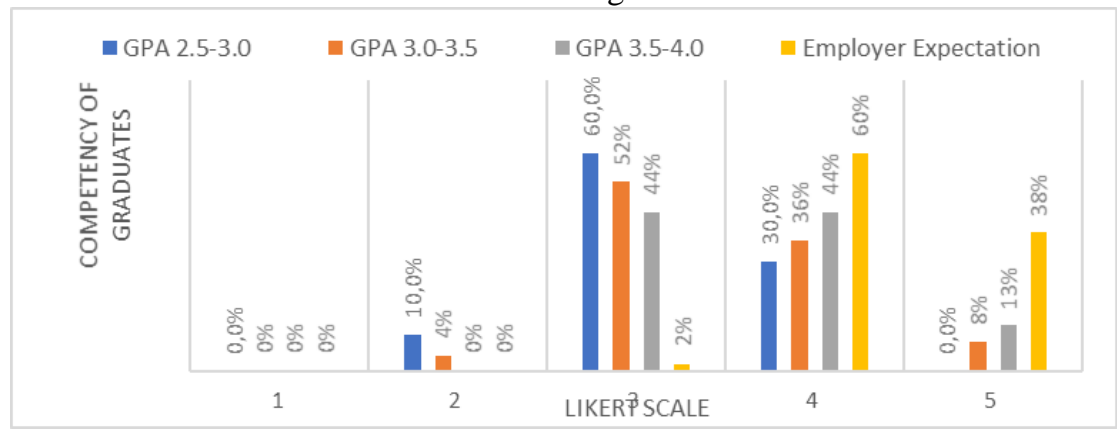

\section{Written Knowledge}

Written knowledge is also found to be very important to employers. $80 \%$ of employers think written knowledge is important or extremely important to be successful in the job. But there are some employers (12\%) who think written knowledge is slightly important. The plot shows that $19 \%$ of good performing students and 8\% of average performing students received excellent ( 5 on Likert scale) from their employers. The rest of the students show a kind of mixed competency. About $40 \%$ of all category students received 4 on the Likert scale and nearly $35 \%$ of all category students received 3 on the Likert scale. This suggests, for written knowledge, possibly GPA doesn't hold any relation with the competency of graduates.

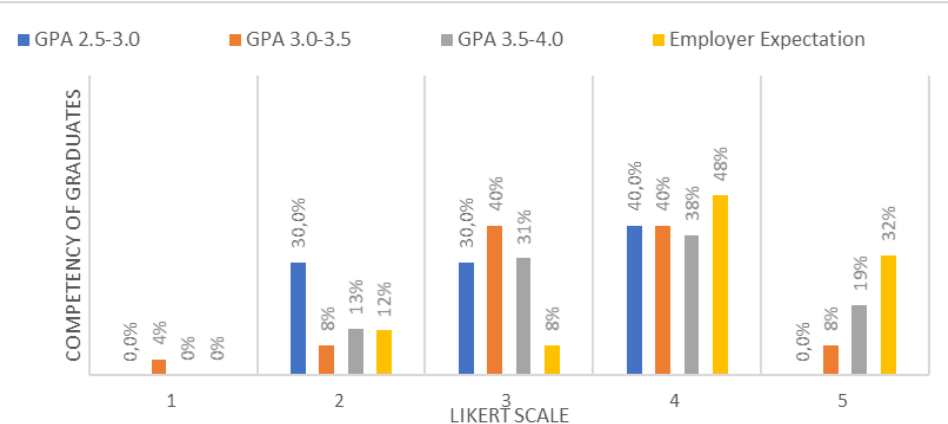

Figure 6. Competency of graduates and employer's expectation vs Likert scale for written knowledge

\section{Presentation skill}

Figure 7 shows a total $84 \%$ of employers gave presentation skills to be moderately important or more (3 or more on Likert scale). The competency of good performing and average performing students is very good for this skill. Total $63 \%$ and $48 \%$ of good performing and average performing students 
respectively received a very good or excellent rating from the employer. Surprisingly $80 \%$ of the poor performing students get good (Likert scale 3) competency from the employer. So, it is clear that for presentation skills, GPA holds a positive relationship with the competency of graduates.

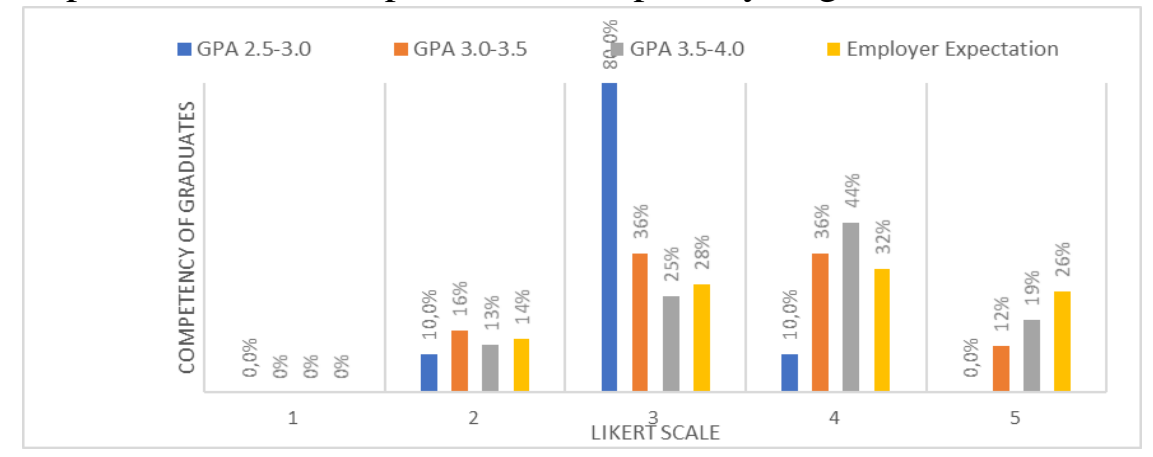

Figure 7. Competency of graduates and employer's expectation vs Likert scale for presentation skill

\section{Ability to work in a team}

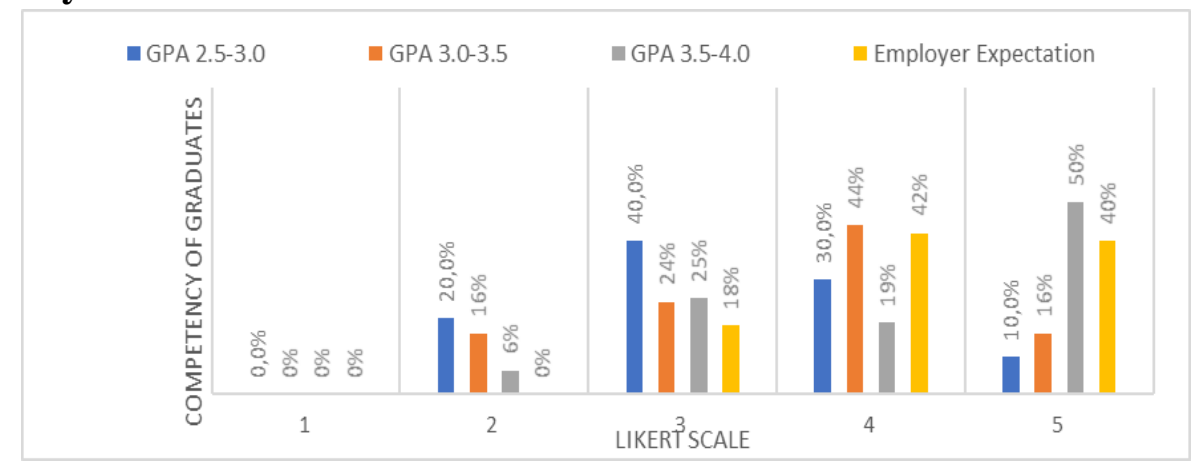

Figure 8. Competency of graduates and employer's expectation vs Likert scale for teamwork

Figure 8 shows a total $80 \%$ of employers expect or consider teamwork is important or extremely important (4 and 5 in Likert scale). The figure also suggests that a total of $69 \%, 60 \%$ and $40 \%$ of the good performing, average performing, and poor performing students show very good or excellent teamwork, respectively. So, it is clear GPA also indicates how good a team player an employee will be in the work field. 


\section{Leadership}

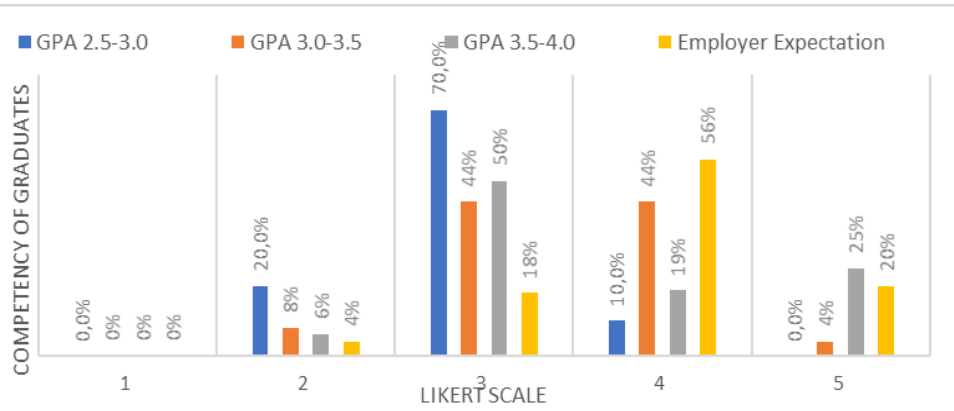

Figure 9. Competency of graduates and employer's expectation vs Likert scale for leadership

Figure 9 clearly shows that $76 \%$ of employers believe leadership quality is important or extremely important for employees. To analyze the competency, average performing students (48\%) showed very good or excellent leadership than the good performing students (44\%). But most of the students, $50 \%$ of good performing students, $44 \%$ of average performing students and $70 \%$ of the poor-performing students, show good leadership qualities. So, it is tough to say that GPA can predict the leadership quality of any employee. It was evident since, in calculating GPA, leadership quality cannot be included.

\section{Empathy}

Here, $96 \%$ of the total employer think that being empathetic is moderately important or important (3 and 4 on the Likert scale) in industry. The plot also suggests the empathetic nature of the graduates. From the field, it is seen $87 \%, 76 \%$ and $60 \%$ of the good performing, average performing, and poor performing graduates are empathetic or very empathetic (Likert scale 3 or 4). Though empathy is never considered to calculate GPA even indirectly, it seems that good performing students are more empathetic than average or poor-performing students. In turn, empathy shows a positive relationship with GPA.

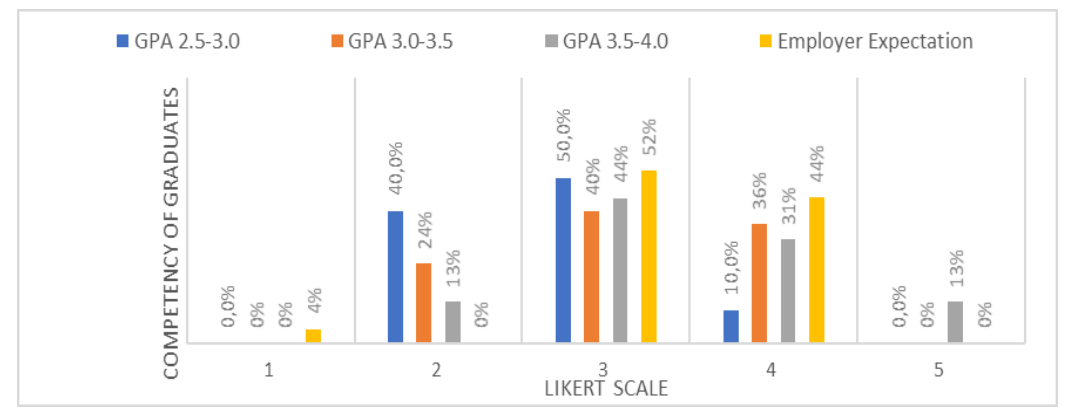

Figure 10. Competency of graduates and employer's expectation vs Likert scale for empathy 
Here, $96 \%$ of the total employer think that being empathetic is moderately important or important (3 and 4 on the Likert scale) in industry. The plot also suggests the empathetic nature of the graduates. From the field, it is seen $87 \%, 76 \%$ and $60 \%$ of the good performing, average performing, and poor performing graduates are empathetic or very empathetic (Likert scale 3 or 4). Though empathy is never considered to calculate GPA even indirectly, it seems that good performing students are more empathetic than average or poor-performing students. In turn, empathy shows a positive relationship with GPA.

\section{Motivation ability}

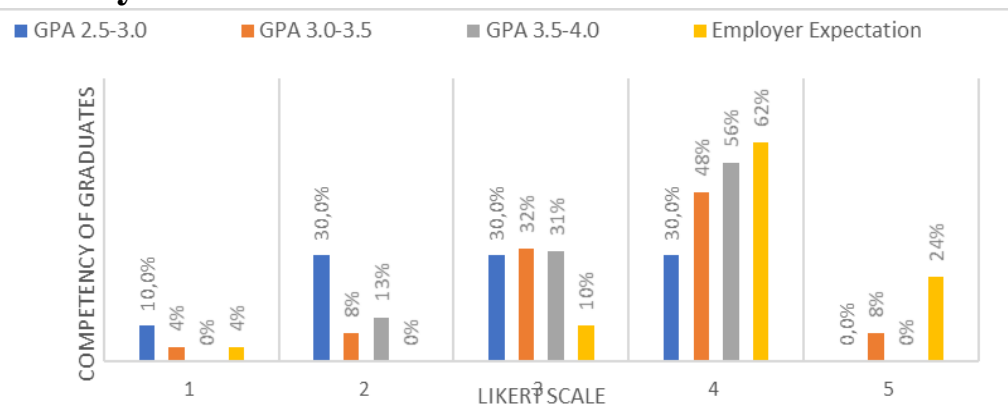

Figure 11. Competency of graduates and employer's expectation vs Likert scale for motivational ability

In Figure 11, the employer's expectation and graduate's motivation for motivation are presented over the Likert scale. As expected, $86 \%$ of the total employers consider motivation an important or highly (4 or 5 on Likert scale) important quality. If we look into the competency of graduates, we see $56 \%$ of the good performing students show very good motivation ability while $31 \%$ show good motivation ability. Surprisingly there are $8 \%$ of average performing students showed excellent motivation ability, and $48 \%$ showed very good motivation. Poor performing students showed a lack of motivation ability having $30 \%$ in each average, good and very good motivation ability status. We found $10 \%$ of poor-performing students and $4 \%$ average performing students who showed poor motivation. So, it can be concluded that motivation also maintains a positive relationship with GPA. 


\section{Reliability}

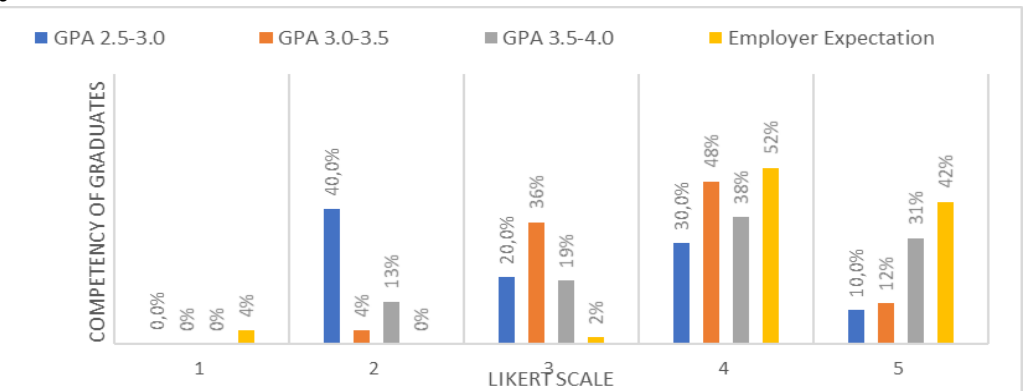

Figure 12.Competency of graduates and employer's expectation vs Likert scale for reliability

Figure 12 shows the employer's expectation and graduate's competence for reliability over the Likert scale. It is visible that $94 \%$ of the employers give reliability as Likert scale 4 and 5 that is important or extremely important. The plot also shows the graduate's competency in this virtue. Good performing students showed high competency securing 31\% and 38\% of the students getting very good and excellent from the employer. For average performing students, $12 \%$ received excellent, $48 \%$ very good and $36 \%$ received well on reliability from the employer. For poor performing students, $40 \%$ received an average from the employer. So, it is clear that reliability has a positive relationship with GPA resulting in good performing students being more reliable than poor-performing students.

\section{Appreciation of ethical values}

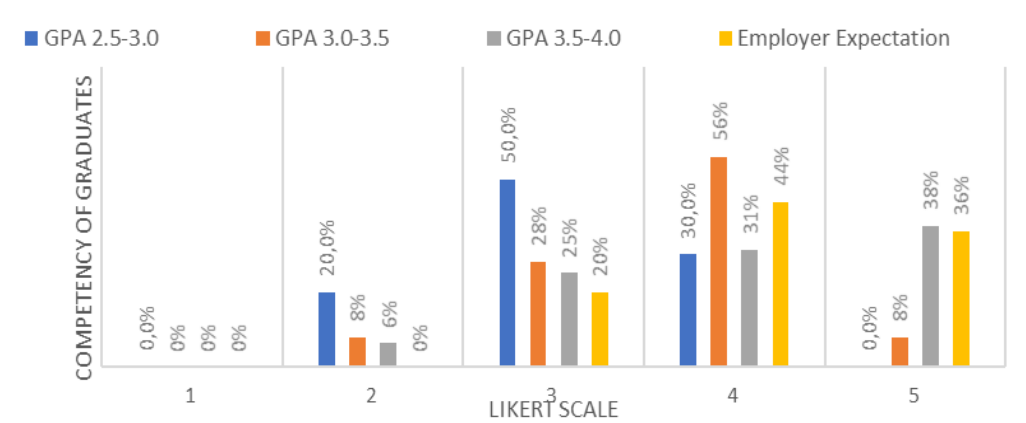

Figure 13. Competency of graduates and employer's expectation vs Likert scale for appreciation of ethical value

Figure 13 shows the employer's expectation and graduate competence to appreciate ethical value over the Likert scale. A total of $80 \%$ of the employers think appreciation of ethical value is important or extremely important, while the rest $20 \%$ think it is moderately important. To look into the graduate's competency, we find that $38 \%$, 35\%, and $21 \%$ of good performing students 
received excellent, very good and good performance (5,4,3 in Likert scale). So it is clear that good performing students are highly competent. Among the average performing students, $8 \%, 56 \%$, and $28 \%$ students got excellent, very good and good performance (5,4,3 on Likert scale) respectively. So they are also very competent. Among the poor performing students, no one received excellent grades from the employers. Most of them (50\%) received good from their employers. So, it looks that appreciation of ethical values has a positive relation with GPA.

\section{Adaptability}

Figure 14 shows the expectancy of employer and graduate's competency with respect to adaptability. For the plot it is clear $98 \%$ of the employers think adaptability is important or extremely important (4 or 5 on Likert scale). For the graduate's competency, we see a mixed response. 31\%, $38 \%$ and $21 \%$ of the good performing students received excellent, very good and good competence (Likert scale 5,4 and 3) from the employer. Among the average performing students, 28\%, 32\% and 36\% received excellent, very good and good competence for adaptability. Among the poor performing students, $10 \%, 50 \%$, and $30 \%$ got excellent, very good and good competence from the employer. So it seems that all the graduates are fairly competent in adaptability. This data concludes there is possibly no relationship between adaptability and GPA.

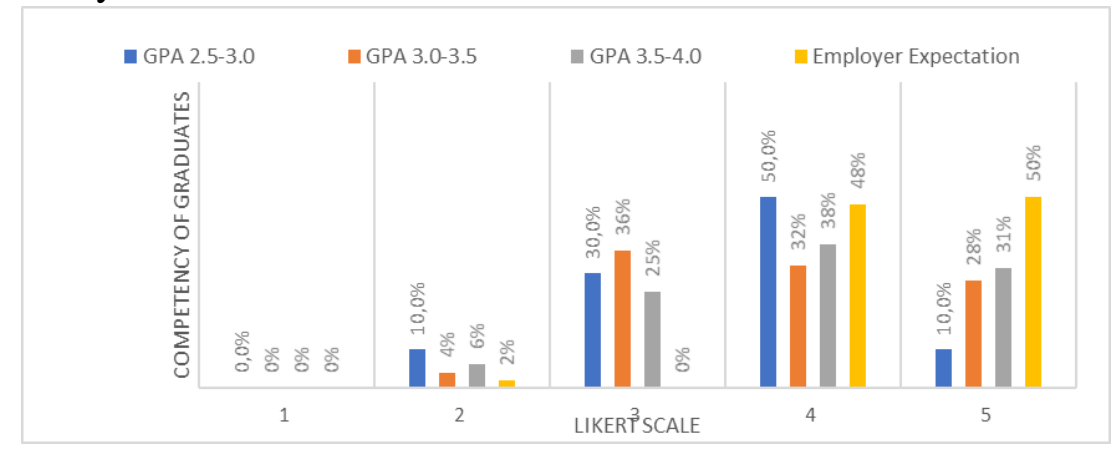

Figure 14. Competency of graduates and employer's expectation vs Likert scale for adaptability 


\section{Time management}

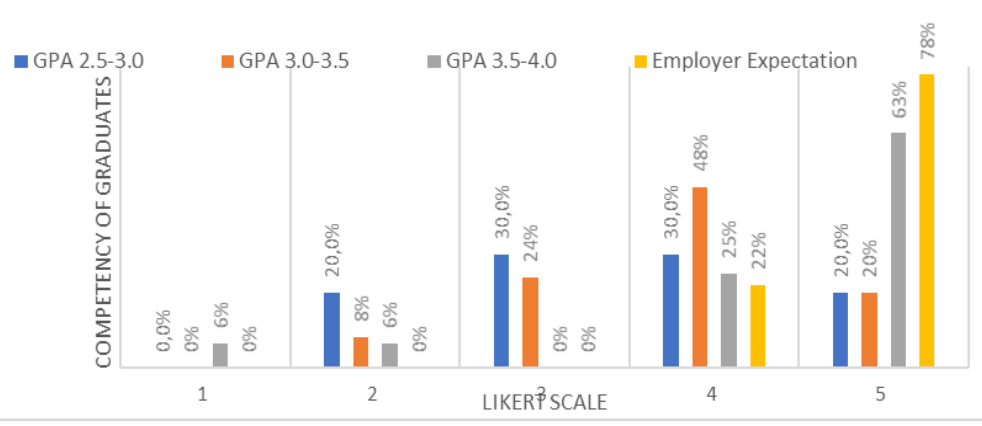

Figure 15. Competency of graduates and employer's expectation vs Likert scale for time management

Figure 15 clearly shows $100 \%$ of the employers consider time management as important or extremely important (4 and 5 on Likert scale). Good performing students showed their excellent competence by $63 \%$ of the total students receiving excellent from the employer. Although $6 \%$ of the good performing students received poor ratings ( 1 on the Likert scale), $88 \%$ of the total good performing students received very good or excellent from the employer. Average performing students also showed good competency by $20 \%, 48 \%$, and $24 \%$ of the students receiving excellent, very good and good remarks from the employer. The poor-performing students got mixed comments. 20\%, 30\%, 30\% and 20\% of the total students received excellent, very good, good and average remarks from the employers. So it can be concluded that time management quality is positively related to GPA. Better performing students are expected to have more time management skills.

\section{Judgment}

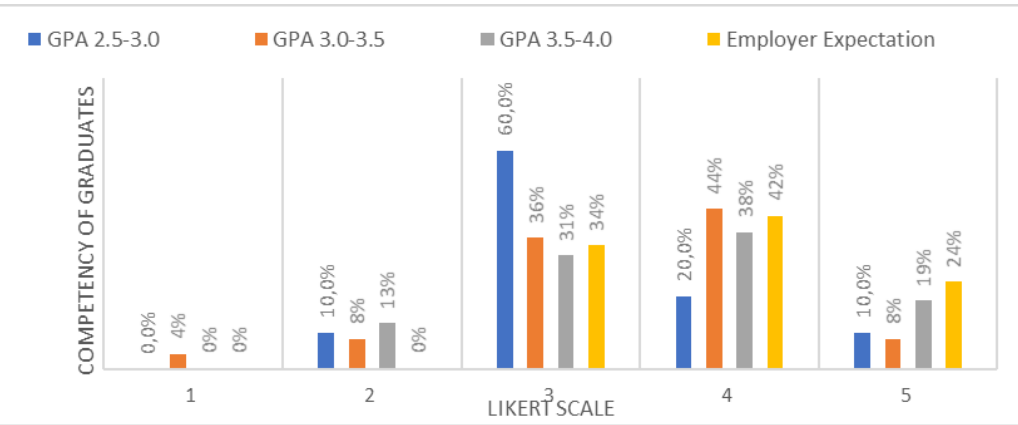

Figure 16. Competency of graduates and employer's expectation vs Likert scale for judgment

Total $24 \%, 42 \%$ and $34 \%$ of the employers think judgement is extremely important, important and moderately important (Likert scale 5,4 and 3), respectively. So, it is clear that the judgment of the employee is 
important to the employers. Now to see the competency of the graduates, the plot shows a mixed nature. Total $19 \%, 38 \%$ and $31 \%$ of the good performing students received excellent, very good and good (Likert scale 5,4 and 3). In comparison, $8 \%, 44 \%$ and $36 \%$ of the average performing students received excellent, very good and good (Likert scale 5,4 and 3), respectively. Close performance is also observed for poor-performing students with $10 \%, 20 \%$, and $60 \%$ of them received excellent, very good and good (Likert scale 5,4 and 3 ). So a total of $57 \%$ of good performing students, $52 \%$ of average performing students and $30 \%$ of the poor performing students received very well or excellent from the employer. Nearly $40 \%$ of good and average performing students and $60 \%$ of poor-performing students received well. So, it can be concluded that judgment may have no relationship with GPA.

\section{Problem formulation, solving and decision-making skills:}

Here, $38 \%, 36 \%, 18 \%$ and $8 \%$ of the employers consider this skill is extremely important, important, moderately important and slightly important (Lyert scale 5,4,3 and 2), respectively. The plot also shows $87 \%$ of the good performing students, $88 \%$ of the average performing students and $70 \%$ of the poor performing students received excellent, very good and good (Likert scale 5,4 and 3) from the employer. So, it can be said there may be a weak positive relation of problem formulation, solving and decision-making skills with GPA.

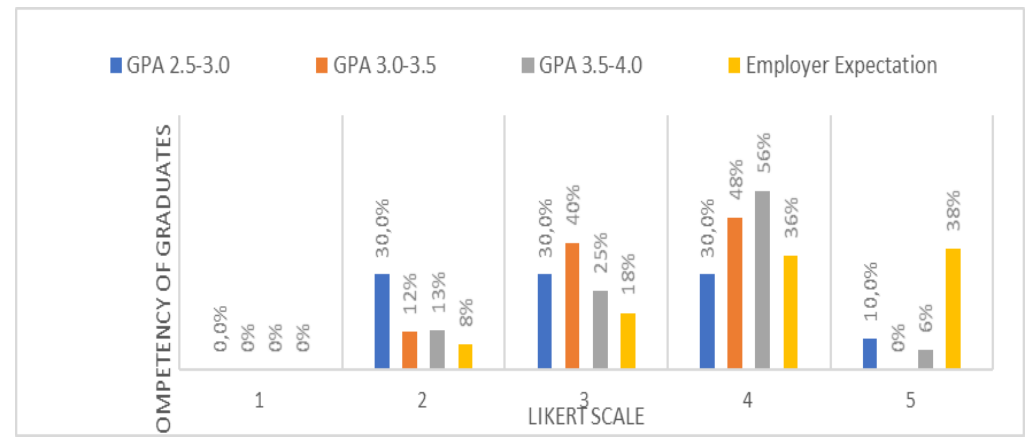

Figure 17. Competency of graduates and employer's expectation vs Likert scale for problem formulation, solving and decision-making skill

\section{Collecting and analyzing appropriate data}

Figure 18 shows that $86 \%$ of the employers think this quality is either extremely important or important (Likert scale 5 and 4). The plot also suggests the dominance of good performing students for this quality. Total 69\%, 56\% and $50 \%$ of good performing, average performing, and poor performing received excellent and very good remarks from the employee. So, it is visible that collecting and analyzing appropriate data skills has a positive relationship with GPA. 


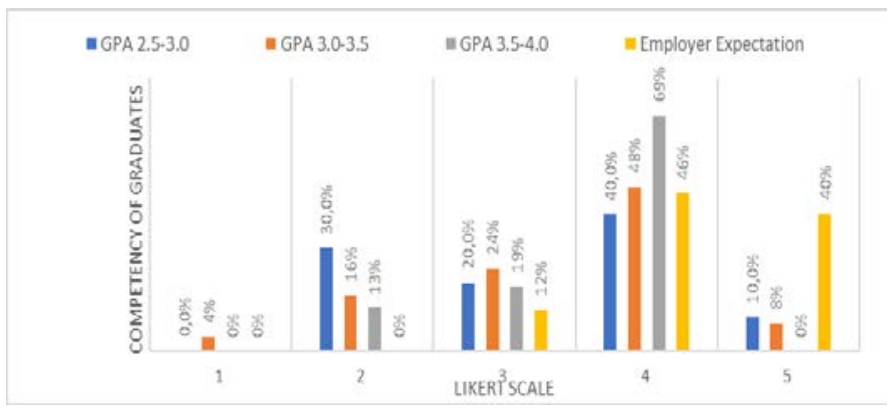

Figure 18. Competency of graduates and employer's expectation vs Likert scale for collecting and analyzing appropriate data

\section{Ability to link theory to practice}

Figure 19 indicates that employees do not consider this ability very important. $24 \%, 36 \%, 30 \%$ and $10 \%$ of the total employer think this ability to be extremely important, important, moderately important and slightly important (5,4,3 and 2 on Likert scale), respectively. Graduate's competency also shows a mixed type of nature. $25 \%$ of the good performing students and $8 \%$ of average performing students received excellent from the employer, while most of the students received average or good remarks from the employer. So, it can be concluded that the ability to link theory to practice a skill is positively related to GPA, but the relationship is weak.

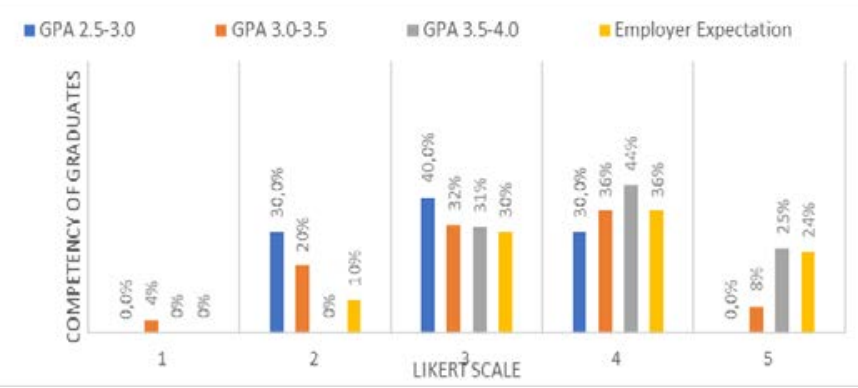

Figure 19. Competency of graduates and employer's expectation vs Likert scale for the ability to link theory to practical

\section{Discipline}

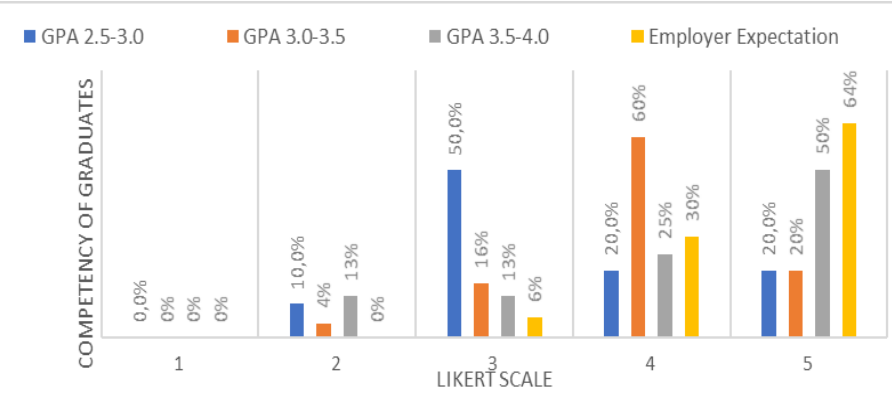

Figure 20. Competency of graduates and employer's expectation vs Likert scale for discipline 
$64 \%$ of the employers think discipline is extremely important, while $30 \%$ think this is important. Good performing students are very disciplined, 50\% of them received excellent and 25\% received very good remarks. Average performing students also did very well; $20 \%$ received excellent, while $60 \%$ received very good remarks. Poor performing students received various remarks, while half of them received average remarks from the employer. So it is clear that discipline has a solid positive relationship with GPA. Good performing students are expected to be more disciplined than average or poorperforming students.

\section{Sense of responsibility}

$62 \%$ of the employers think a sense of responsibility is extremely important, while $32 \%$ think it is important. The competency of good performing and average performing students are found to be good. A total of $69 \%$ and $68 \%$ of good performing and average performing students respectively received excellent or very good remarks from the employers. Most of the poor performing students (50\%) received good remarks. So, it can be concluded again that a sense of responsibility has a positive relation with GPA.

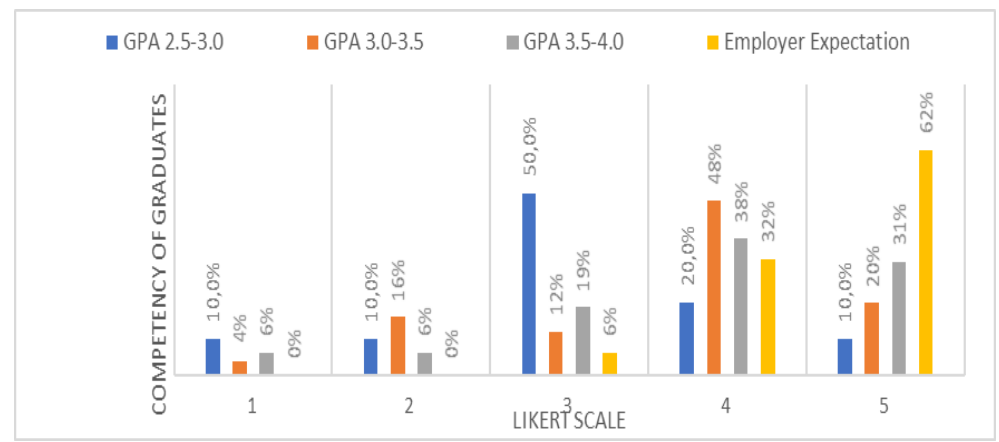

Figure 21. Competency of graduates and employer's expectancy vs Likert scale for sense of responsibility

\section{Future Work}

In the current study, the authors considered fifty graduates from a reputed university of Bangladesh as sample size and their competency in overall textile job sectors. The textile field is an enormous field with several sub-branches. So, the study should be extended soon with a higher number of students taking from other institutes and covering different textile job sectors of the country.

\section{Conclusion}

During employment, the grades they obtained in their university are the primary assessing tool the employers have. Unfortunately, educators around 
the globe are still in a dilemma whether good grades in university are a good indicator of future job performance? A survey-based investigation is performed in the current study to shed some light on this matter in the textile industry in Bangladesh. The authors used twenty dimensions of quality to see how important they are to the employers and how competent the graduates are on these quality dimensions. The study showed that with a few exceptions, for most of the quality dimensions, students with good academic results are better competent than graduates with average and poor academic results. From this, it can be concluded that a good university grade from this university can be considered to forecast good job performance in the future in the textile sector.

\section{Acknowledgement}

The authors acknowledge the Institutional Quality Assessment Cell (IQAC), University Grants Commission of Bangladesh and World Bank for funding and providing guidelines for this study.

\section{References:}

1. 'In the eyes of the beholder': the influence of academic performance and extracurricular activities on the perceived employability of Chinese business graduates. (2018). Asia Pacific Journal of Human Resources, 57(4).

2. Alex Tymon, S. B. (2016). Improved academic performance and enhanced employability? The potential double benefit of proactivity for business graduates. Teaching in Higher Education, 21(8), 915-932.

3. Alexandre Gareau, M. C. (2019). The detrimental effect of academic procrastination on subsequent grades: the mediating role of coping over and above past achievement and working memory capacity. Anxiety, Stress, \& Coping, 32(2), 141-154.

4. Brooke Harris-Reeves, J. M. (2017). Brief work-integrated learning opportunities and first-year university students' perceptions of employability and academic performance. Australian Journal of Career Development, 26(1), 32-37.

5. Carol P. Huie, T. C. (2020). The Impact of Tacit Knowledge Sharing on Job Performance. International Journal on Social and Education Sciences, 2(1), 34-40.

6. Faith, J. A. (2014). Perceived Relationship Between Employee Academic Qualifications And Job Perfomance In Mukuru Slums Development Projects, Nairobi County.

7. Filip Lievens, P. R. (2012). The Validity of Interpersonal Skills Assessment Via Situational Judgment Tests for Predicting Academic Success and Job Performance. Journal of Applied Psychology, 97(2), 460-468. 
8. Georg Krammer, M. S. (2016). Realistic job expectations predict academic achievement. Learning and Individual Differences, 51, 341348.

9. K. Subhash Bhagavan, J. T. (2020). Predictive analysis of student academic performance and employability chances using HLVQ algorithm. Journal of Ambient Intelligence and Humanized Computing.

10. Lekhanath Khanal, P. D. (2017). Knowledge Management, Employee Satisfaction and Performance: Empirical Evidence from Nepal. Saudi Journal of Business and Management Studies, 2(2), 82-91.

11. Lina Al-Abbadia, R. A. (2020). Knowledge management processes and innovation performance: The moderating effect of employees' knowledge hoarding. Management Science Letters, 10, 1463-1472.

12. Luisa H. Pinto, D. C. (2017). Perceived employability of business graduates: The effect of academic performance and extracurricular activities. Journal of Vocational Behavior, 99, 165-178.

13. Mafeng Dauda Gyemanga, O. L. (2020). The roles of dynamic capabilities, innovation, organizational agility and knowledge management on competitive performance in telecommunication industry. Management Science Letters, 10, 1533-1542.

14. Mir Hamid Reza Torabia, A. K. (2016). An Investigation of the Impact of Knowledge Management on Human Resource Performance in Management of Keshavarzi Bank Branches in Tehran. Procedia Social and Behavioral Sciences, 230, $471-481$.

15. Nathan R. Kuncel, S. A. (2004). Academic Performance, Career Potential, Creativity, and Job Performance: Can One Construct Predict Them All? Journal of Personality and Social Psychology, 86(1), 148161.

16. Tripti Mishra1, D. K. (2017). Students' Performance and Employability Prediction through Data Mining: A Survey. Indian Journal of Science and Technology, 10(24). 